\title{
Kentucky pharmacists' opinions of the potential reclassification of pseudoephedrine as a legend drug
}

\author{
Kathleen E. Monson, PharmD, MPA [Inpatient Pharmacist], \\ St. Elizabeth Healthcare, Edgewood, KY; at the time of the research, she was a student \\ pharmacist, College of Pharmacy, University of Kentucky, Lexington \\ Patricia R. Freeman, PhD [Clinical Associate Professor], \\ College of Pharmacy, Institute for Pharmaceutical Outcomes and Policy, University of Kentucky, \\ Lexington
}

\section{Amie J. Goodin, MPP [Research Coordinator], \\ College of Pharmacy, Institute for Pharmaceutical Outcomes and Policy, University of Kentucky, Lexington \\ Jeffery Talbert, PhD [Director], and \\ College of Pharmacy, Institute for Pharmaceutical Outcomes and Policy, University of Kentucky, Lexington}

\section{Karen Blumenschein, PharmD [Associate Professor]}

College of Pharmacy, Institute for Pharmaceutical Outcomes and Policy, University of Kentucky, Lexington

\section{Abstract}

Objectives-To collect and analyze Kentucky pharmacists' opinions of the effectiveness of current methamphetamine precursor controls, to analyze proposed legislation to make pseudoephedrine (PSE) a legend drug, and to analyze the potential impact of such legislation on pharmacy practice and patients.

Design-Descriptive, nonexperimental survey study.

Setting-Kentucky; June through October 2012.

Participants—431 Kentucky community pharmacists.

Intervention-Mailed survey.

Main outcome measures-Perceived efficacy of current methamphetamine precursor controls, anticipated impact on individual pharmacy practices and patients of proposed legislation to make PSE available by prescription only, and current opinions about the proposed legislation.

Correspondence: Kathleen E. Monson, PharmD, MPA, 1 Medical Village Drive, Edgewood, KY 41017. Fax: 859-301-3958. kathleen.monson@gmail.com.

Disclosure: The authors declare no conflicts of interest or financial interests in any product or service mentioned in this article, including grants, gifts, stock holdings, or honoraria.

Previous presentation: American Society of Health-System Pharmacists Midyear Clinical Meeting, Las Vegas, NV, December 2-6, 2012. 
Results-Analysis of 431 community pharmacists showed that approximately $77 \%$ believed proposed legislation to make PSE available by prescription only would be effective in reducing methamphetamine abuse and methamphetamine-related laboratory incidents, with 56.2\% indicating support for the proposed legislation. Pharmacists practicing in chain pharmacies were 2.9 times more likely to support the legislation than pharmacists practicing in independent pharmacies. Additional factors influencing pharmacist support included Kentucky region of practice, anticipated impact on time spent on PSE activities, pharmacy profit, methamphetamine abuse, and methamphetamine-related laboratory incidents. Pharmacists practicing in regions of Kentucky associated with higher methamphetamine abuse appear to more strongly support the proposed legislation.

Conclusion-Pharmacists are at the frontline of PSE distribution. Gaining a better understanding of issues surrounding the distribution of PSE will enhance the likelihood that future legislation may be crafted to reduce methamphetamine production, laboratory incidents, and abuse while minimizing inconvenience and cost.

\section{Keywords}

Community pharmacy; methamphetamine; pseudoephedrine; precursor regulation; over-thecounter; prescription

Methamphetamine is a Schedule II controlled substance that is recognized as a major drug of abuse. It is often produced illicitly in small, clandestine laboratories through the use of precursor chemicals, including pseudoephedrine (PSE), an over-the-counter (OTC) decongestant. ${ }^{1}$ Small quantities of methamphetamine are relatively easy and cheap to manufacture, requiring little knowledge, skill, or equipment. However, clandestine laboratories are extremely dangerous because of the nature of the volatile chemicals used in the manufacturing process, which can result in fires, explosions, and environmental contamination. ${ }^{1}$

Some efforts to curb methamphetamine abuse are aimed at controlling access to PSE used in illicit methamphetamine production. A series of federal methamphetamine precursor laws that impact PSE distribution at both the wholesale and retail level has been implemented during the past decade, including increased reporting and record-keeping requirements, mandatory registration with the U.S. Drug Enforcement Administration, packaging requirements, quantity limits, and placement of PSE-containing products behind the pharmacy counter. ${ }^{2}$

In addition to federal legislation, Kentucky requires electronic tracking and the blocking of PSE sales that exceed the legal limit. In 2008, Kentucky became the first state to implement electronic tracking with Meth-Check, which is now known as National Precursor Log Exchange (NPLEx). ${ }^{2}$ Kentucky also mandates a stricter PSE quantity limit than the federal limit of 9 grams per month. As of July 2012, Kentucky law limits PSE monthly sales to 7.2 grams per individual. ${ }^{3} \mathrm{New}$ legislation in the state includes the creation of a methamphetamine registry for those convicted of a methamphetamine-related crime and blocks the sale of PSE to individuals listed in the registry. ${ }^{4}$ 
Despite both federal and state legislation aimed at controlling access to methamphetamine precursors, illicit manufacturers have found alternate methods to produce methamphetamine and obtain PSE, circumventing the laws and tracking systems. "Smurfing" is a popular practice for obtaining sufficient quantities of PSE for methamphetamine production ${ }^{5}$; it involves having several individuals purchase legal amounts of PSE.

Methamphetamine cases in Kentucky increased from 6\% of total drug cases in 2007 and 2008 to $9 \%$ in 2009 and $11 \%$ in $2010 .{ }^{5}$ Additionally, the number of laboratory seizures in Kentucky has risen from 428 in 2008 to 741 in 2009 and 1,078 in 2010, with production traditionally associated with western and south central Kentucky and indicators demonstrating production increasing in eastern Kentucky. ${ }^{5}$ Recently proposed state legislation to change PSE from nonprescription to legend status was unsuccessful and highly controversial.

Proponents of requiring a prescription to purchase PSE argue that data from Oregon and Mississippi-the only states with such a requirement—indicate efficacy in reducing laboratory incidents and associated hazards. ${ }^{2}$ Additional data show a decrease in methamphetamine-related crimes, arrests, and admissions to substance abuse treatment facilities following implementation of prescription-only PSE legislation. ${ }^{2}$ However, further data are needed to ensure the reduction in methamphetamine indicators is sustained. Proponents of prescription-only legislation also argue that a majority of the OTC PSE purchased is used for methamphetamine production. ${ }^{2}$ Proponents believe OTC PSE represents a significant cost to society by creating hazards for the public and law enforcement.

Opponents of requiring a prescription to obtain PSE reason that the legislation would place additional burdens on physicians, pharmacists, insurance companies, and consumers. ${ }^{2,6,7}$ Some opponents also believe consumers would face added costs and inconveniences for repeat doctor visits to obtain prescriptions for PSE. Additionally, some patients could opt for less effective treatment or no treatment at all, resulting in a lower quality of life.

Data are available regarding consumers' opinions of various methamphetamine precursor controls, yet there is limited understanding of health care providers' opinions. ${ }^{6,7}$ Community pharmacists are knowledgeable of the burdens surrounding PSE distribution and may be significantly affected by changes in distribution. As a result, it is important to understand community pharmacists' opinions regarding the proposed prescription-only PSE legislation. Community pharmacists have experience providing PSE to patients and maintaining PSE records. Furthermore, community pharmacists and pharmacy staff are in the unique position to deny access to PSE, which can lead to uncomfortable situations.

This study seeks to identify challenges and the perceived efficacy of current methamphetamine precursor control policies, implications of proposed legislation to make PSE available by prescription only, and pharmacist factors associated with support and opposition of the legislation. 


\section{Objectives}

The aim of this study was to gain a better understanding of Kentucky community pharmacists' opinions surrounding methamphetamine precursor control. Areas surveyed included effectiveness of current methamphetamine precursor controls, effectiveness of proposed legislation to make PSE a legend drug, and the anticipated impact of making PSE a legend drug on individual Kentucky pharmacists' practice and patients. The final aim was to investigate the impact of various factors on pharmacists' support for the legislation to make PSE available by prescription only.

\section{Methods}

This study used survey methodology to investigate pharmacists' opinions of methamphetamine precursor controls. The research was approved by the University of Kentucky Institutional Review Board.

\section{Survey instrument}

Survey questions were derived from a previous survey assessing pharmacist opinions about prescription drug monitoring programs. ${ }^{8}$ Before implementation, the survey was reviewed by pharmacists and researchers, and their comments were incorporated into the final version. Survey questions included perceived efficacy of current methamphetamine precursor controls, anticipated impact on individual pharmacy practice and patients of proposed legislation to make PSE available by prescription only, and current opinion regarding the proposed legislation.

The majority of survey questions were fixed-response, and various types of response categories were used, including checklists, Likert-type scales, and multiple choice. Three questions were partially open-ended with the option to select "other" and provide an alternative written answer. One contingency question that was purely open-ended asked why respondents were unsure of their support for, or opposition to, a law requiring a prescription to purchase PSE. Open-ended questions were also asked about average number of prescriptions filled per day, average number of PSE purchases per day, county of practice, description of practice site, and year of professional degree.

\section{Sample}

For a nominal fee, we obtained from the Kentucky Board of Pharmacy a list of all pharmacists licensed in the Commonwealth of Kentucky. Pharmacists with an out-of-state practice address were removed from the list before sampling.

We used Stata v11.0 software (StataCorp, College Station, TX) to draw a simple random sample of pharmacists $(n=2,000)$ from the list of all licensed pharmacists in Kentucky. All surveys were conducted anonymously, with no identifying information collected.

Procedure

A cover letter, survey, and paid business-reply envelope were mailed to the sample of pharmacists in June 2012, with a reminder/thank-you postcard mailed out approximately 2 
weeks later. Survey collection ended October 2012. Returned surveys were entered and maintained in a Research Electronic Data Capture (REDCap) survey instrument hosted by the University of Kentucky. ${ }^{9}$ A unique identification number was assigned to each returned survey.

\section{Analysis}

Stata v11.0 statistical software was used to analyze the data. Descriptive statistics were generated, including frequencies and proportions. Bivariate analyses were conducted using the chi-square test and $t$ test. Binomial, multivariate logistic regression was performed to investigate the impact of independent variables on pharmacists' support for the legislation to make PSE available by prescription only. Observations missing independent variable values were dropped in the regression model.

Dependent variable-The dependent variable used in the binomial, multivariate logistic regression model was pharmacists' support for the legislation to make PSE available by prescription only. Support for the legislation was assessed using the survey question, "At this time, do you support or oppose a law that would require a prescription in order to obtain PSE?" Respondents could select "support," “oppose,” or "unsure.” Respondents selecting "unsure" were not included in regression analysis.

Independent variables-The following independent variables, hypothesized to have the strongest relationship with position on the proposed legislation, were used in the binomial, multivariate logistic regression model: chain versus independent pharmacist status, anticipated impact of legislation on time spent on PSE-related activities, anticipated impact of legislation on pharmacy profit, Kentucky region of pharmacy practice, anticipated impact of legislation on methamphetamine abuse and laboratory incidents, confidence in identifying patients purchasing PSE for a legitimate medical purpose, and grams of PSE sold per county resident.

Kentucky regions were derived from the Substance Abuse and Mental Health Services Administration's National Survey on Drug Use and Health ${ }^{10}$ (Figure 1). Grams of PSE sold per county resident were obtained from NPLEx. Other independent variables were derived directly from survey responses.

\section{Results}

A total of 608 pharmacists completed the survey, and 10 surveys were returned as undeliverable, yielding a $30.6 \%$ response rate. Pharmacists reporting a practice site as "hospital" or "other," as well as those not designating a practice site, were removed from analysis $(n=177)$ for lack of being actively engaged in PSE dispensing. The final sample for analysis included 431 pharmacists practicing in a community pharmacy (independent, chain, or supermarket/mass retailer). Chain and supermarket/mass retailer practice sites were combined for simplicity and are hereafter referred to as chain pharmacies. 


\section{Sample characteristics}

Table 1 describes characteristics of responding community pharmacists and reported practice site characteristics. Chain pharmacists represented $60.8 \%$ of those responding to the survey. Independent and chain pharmacists differed significantly in the number of prescriptions dispensed per day, number of PSE purchases made per day, and number of years in practice.

\section{Current PSE control efficacy}

Pharmacists were asked regarding perceived efficacy of current PSE controls-including the NPLEx electronic tracking system and current quantity limitations-in reducing methamphetamine abuse and laboratory incidents. Few pharmacists $(<4 \%)$ reported that current PSE controls were "very effective" in reducing methamphetamine abuse or laboratory incidents. In regard to NPLEx and current quantity limitations, approximately $57 \%$ and $45 \%$, respectively, found them at least "somewhat effective."

\section{Efficacy of legislation}

When asked about the anticipated efficacy of making PSE a legend drug, approximately $77 \%$ of pharmacists reported that the legislation would be at least "somewhat effective" at reducing methamphetamine abuse and laboratory incidents (Figure 2).

\section{Impact of legislation on pharmacy}

Pharmacists were asked about the anticipated impact on their pharmacy practice and patients of making PSE available by prescription only. Nearly one-half (48.8\%) reported an anticipated decrease in time spent on PSE-related activities if PSE were available by prescription only, while $31.7 \%$ reported an anticipated increase in time spent on PSE-related activities. Pharmacists also reported differences in time required to complete one PSE purchase using NPLEx, ranging from less than 1 minute to more than 4 minutes.

The largest proportion (47.9\%) of pharmacists reported an anticipated neutral financial impact if PSE were to be made available by prescription only, while nearly one-quarter (23.8\%) reported being uncertain of the financial impact on their pharmacy if a prescription were required to obtain PSE.

Pharmacists reported that patients would be impacted in a variety of ways if PSE were prescription only. A majority (72.2\%) said patients would experience increased time at physicians' offices obtaining a prescription for PSE. Additionally, $69.4 \%$ and $67.3 \%$ of pharmacists, respectively, reported limited access to PSE for illicit and legitimate users. More than one-half of pharmacists (56.8\% and 55.7\%, respectively) reported an anticipated increase in patient time spent at the pharmacy obtaining a prescription for PSE and an increase in patient costs.

\section{Opinions about proposed legislation}

The majority (56.2\%) of pharmacists supported proposed legislation to make PSE available by prescription only, while $30.7 \%$ were opposed. The remaining $13.1 \%$ reported being unsure of their support of or opposition to the legislation. 
If respondents' reasoning for their stance on the proposed legislation was not captured by available survey answers, extra space was provided for further explanation. The vast majority of comments described why respondents opposed or were unsure about the proposed legislation.

Comments generally fell into two major categories. Approximately $35 \%$ of comments indicated that methamphetamine abusers/manufacturers will always find a way around laws. Commenters cited opioids and benzodiazepines as examples of drugs associated with continued abuse and diversion despite prescription requirements. An additional 35\% of comments suggested that implementation of a prescription-only requirement would punish law-abiding citizens.

A less common suggestion was that PSE should be made a controlled substance and tracked electronically. Several comments also suggested that pharmacists should use better professional judgment and deny PSE to individuals thought to be purchasing the precursor with illicit intent. Additionally, several comments expressed concern about increased criminal activity related to making PSE prescription only.

\section{Kentucky location}

Table 2 depicts pharmacists' support or opposition for the legislation by state region. Regions 1 and 3, which include northern Kentucky, Lexington, and Louisville, appear split on the legislation. The remaining regions, including western, eastern, and southern Kentucky, largely support the legislation. The vast majority (86.0\%) of pharmacists in southern Kentucky (region 6) support the legislation.

\section{Multivariate analysis}

Logistic regression was conducted to determine the impact of selected independent variables on pharmacists' support for the proposed legislation to make PSE available by prescription only (Table 3 ).

The logistic regression results show that chain pharmacists were 2.9 times more likely than independent pharmacists to support the legislation. Pharmacists who anticipated no change in time related to PSE activities or a decrease in time related to PSE activities if PSE were to be available by prescription only were 5.09 and 10.57 times more likely to support the legislation, respectively, compared with those who did anticipate a related increase in time.

Although a minority, pharmacists anticipating an associated increase in profit were 9.45 times more likely to support the legislation compared with those anticipating reduced profits. Pharmacists anticipating a neutral financial impact were 4.53 times more likely to support the legislation than those reporting an anticipated decrease in profit.

Pharmacists' region of practice significantly affected their support for the legislation. Compared with pharmacists practicing in region 1, which includes northern Kentucky and Lexington, those practicing in regions 2, 4, 5, and 6 were 4.57, 8.17, 4.04, and 7.99 times more likely to support the legislation, respectively. Similar to region 1, the association 
between location and support for the legislation was not significant in region 3, which includes Louisville.

Pharmacists anticipating the legislation to be "somewhat effective" or "very effective" at reducing methamphetamine abuse were 8.22 and 34.05 times more likely to support the legislation, respectively, compared with those saying the legislation would not be effective at all.

Pharmacists' confidence in identifying patients using PSE for a legitimate medical purpose and grams of PSE sold per county resident were not significantly related to support for the legislation.

\section{Discussion}

Opinions of health care providers, specifically pharmacists, regarding methamphetamine precursor chemical controls are largely unstudied. Available studies have investigated the opinions of Australian and New York pharmacists about OTC PSE regulations that require the logging of PSE purchases. ${ }^{11,12}$

The 20 pharmacists surveyed for the Australian study deemed electronic tracking of PSE sales to be very useful in preventing misuse and abuse of PSE. ${ }^{11}$ However, some reported concern about associated robberies, pharmacist workload increases, and strained relationships with patients. Pharmacists in the New York study said that record keeping for PSE was unduly burdensome and failed to reduce illicit methamphetamine production; however, $67 \%$ said they did see a dramatic decrease in PSE purchases. ${ }^{12}$

Consumer-focused studies funded by the Asthma and Allergy Foundation of America and the Consumer Healthcare Products Association, both of which largely oppose the proposed prescription-only PSE legislation, have shown that a majority of consumers oppose such legislation. ${ }^{6,7}$

Our study aimed to gain a better understanding of Kentucky pharmacists' opinions of methamphetamine precursor controls. We focused on pharmacists practicing in community pharmacies, including independent and chain pharmacies, as such pharmacists are undoubtedly affected by PSE controls.

Significant differences between independent and chain pharmacists were seen in terms of reported number of prescriptions dispensed per day, number of PSE purchases per day, and number of years in practice. It was reported that more PSE was sold daily at chain pharmacies (13.8 purchases per day) compared with independent pharmacies (4.2 purchases per day). This finding could potentially be attributed to differences in store size and the number of customers entering the pharmacies each day. Independent pharmacists reported dispensing an average of 277 prescriptions per day, compared with 355.5 prescriptions per day at chain pharmacies.

Several written comments referenced differences in corporate policies pertaining to PSE distribution at chain pharmacies. One respondent noted, "Independent pharmacists are more 
reserved in selling PSE to patients; chain pharmacists are impacted by store managers/ profit." It is possible that independent pharmacists feel more empowered to develop individual store policies regarding PSE purchases, while chain pharmacists are required to follow corporate policies. Chain pharmacists were also 2.9 times more likely than independent pharmacists to support the legislation to make PSE available by prescription only.

Approximately $77 \%$ of pharmacists reported that the proposed legislation would be at least "somewhat effective" in reducing methamphetamine abuse and laboratory incidents. However, only $56.2 \%$ said they support such a law, while $30.7 \%$ were opposed to it. According to the survey results, $68 \%$ of those opposing the legislation did so out of concern about increased patient inconvenience and cost. Only $23.5 \%$ of those pharmacists against the legislation cited anticipated inefficacy as the primary reason for their opposition.

The primary reason reported by pharmacists for supporting the law was decreased risk of methamphetamine abuse. The second most common reason for support was decreased burden on the pharmacy. The logistic regression model shows that pharmacists anticipating the legislation to be effective in reducing methamphetamine abuse were more likely to support the legislation compared with other pharmacists.

Survey respondents reported a wide range in the amount of time required to complete one PSE purchase using NPLEx - from less than 1 minute to more than 4 minutes. A potential reason for the variation is that pharmacy technicians and interns perform the majority of PSE purchases; therefore, pharmacists may not be fully aware of the time associated with this task. An alternative reason for the variation is the differences among time-saving technology employed by pharmacies.

Pharmacists were also asked to report the anticipated time impact of making PSE available by prescription only. The largest proportion (48.8\%) of pharmacists reported an anticipated decrease in time spent on PSE-related activities if PSE were to be available by prescription only, while $31.7 \%$ reported an anticipated increase in time spent on PSE-related activities.

Prescriptions take approximately 8 minutes to fill, yet nearly $88 \%$ of pharmacists reported that one PSE purchase requires less than 4 minutes. ${ }^{13}$ A significant portion of pharmacists either view prescriptions as taking less time to fill than they actually do or perceive PSE purchases as taking a greater amount of time than was reported in the survey. One potential reason for this disconnect is that PSE purchases represent an interruption in normal pharmacy workflow, which primarily involves filling and dispensing prescriptions.

Logistic regression analysis of support for the legislation found that the region where pharmacies were located had a significant impact on pharmacists' stance. Pharmacists practicing in western, eastern, and southern Kentucky were significantly more likely to support the proposed legislation, with odds ratios for these regions ranging from approximately 4 to 8 when compared with the northern Kentucky and Lexington regions. The descriptive statistics showed that roughly 53\% of pharmacists in the northern Kentucky, Lexington, and Louisville regions supported the legislation, compared with approximately 
$71 \%$ of pharmacists in eastern and western Kentucky and $86 \%$ of pharmacists in southern Kentucky.

Methamphetamine production in the state has been traditionally associated with western and south central Kentucky, but indicators of methamphetamine production and use are increasing in eastern Kentucky. ${ }^{5}$ It appears that pharmacists practicing in those areas most strongly associated with methamphetamine use are more likely to support the legislation to make PSE available by prescription only.

Our study found no significant impact on pharmacists' support for the proposed legislation associated with two independent variables: pharmacist confidence in identifying patients using PSE for a legitimate medical purpose and the amount of PSE (grams) sold per county resident. It was hypothesized that pharmacists confident in identifying patients purchasing PSE for a legitimate medical purpose would not support the legislation. Grams of PSE sold per county resident may not be related to support of the legislation because of lack of pharmacists' awareness of the amount of PSE sold in their county.

\section{Limitations}

Several factors limit interpretation of results of this study.

The survey response rate only represents $30.6 \%$ of the total pharmacist sample. The relatively small sample size $(n=608)$ was further reduced to 431 pharmacists after excluding those practicing in hospitals and "other" settings. This sample size represents strong internal validity for analysis but lacks external validity, as only those Kentucky pharmacists practicing in a community pharmacy setting were included.

Other limitations are simply a result of survey methodology. The primary researcher developed the survey questions. Important response categories might have been omitted from fixed-choice questions. Additionally, responses were mostly inflexible, requiring respondents to select one answer; not much opportunity was provided for discussion or further detail.

Another potential issue is related to the survey methodology's response bias and selfselection bias. There might be inherent differences between pharmacists who responded to the survey and those who opted not to participate. Given the anonymous response design of the study, differences between responders and nonresponders were not assessed.

\section{Conclusion}

Methamphetamine production and abuse is increasing in Kentucky. Proposed PSE prescription-only legislation has resulted in significant controversy. This study provides insight into Kentucky pharmacists' opinions regarding methamphetamine precursor controls. While support for the proposed legislation was far from unanimous, certain pharmacist characteristics appear to be most substantially related to support: chain pharmacy practice; practice site location in western, southern, and eastern Kentucky; anticipated increase in profit and decrease in time spent on PSE activities; and perceived efficacy of the legislation. 


\section{References}

1. Franco, C. [Accessed July 22, 2013] Methamphetamine: background, prevalence, and federal drug control policies. www.ncpc.org/cms-upload/ncpc/File/Methamphetamine-Background, \%20Prevalence,\%20and\%20Federa1\%20Drug\%20Control\%20Policies.pdf

2. Freeman, PR.; Talbert, J. [Accessed July 22, 2013] Impact of state laws regulating pseudoephedrine on methamphetamine trafficking and abuse: a white paper of the National Association of State Controlled Substance Authorities. www.nascsa.org/PDF/ NASCSApseudoephedrineWhitePaper4.12.pdf

3. Kentucky Legislative Research Commission. [Accessed June 25, 2014] Kentucky revised statutes: chapter 218A.1446. www.lrc.ky.gov/statutes/statute.aspx?id=41677

4. Kentucky Legislative Research Commission. [Accessed June 25, 2014] Kentucky revised statutes: chapter 218A.1440. www.lrc.ky.gov/statutes/statute.aspx?id=41676

5. Kentucky State Police. [Accessed July 22, 2013] Methamphetamine manufacturing in Kentucky, 2010. http://odcp.ky.gov/NR/rdonlyres/BCB964F4-8365-4E3D-BC3D-E30A50C19930/0/ MethamphetamineManufacturinginKY2010Final.pdf

6. Stomberg, C.; Sharma, A. [Accessed July 22, 2013] Making cold medicine Rx only did not reduce meth use: analyzing the impact of Oregon's prescription-only pseudoephedrine requirement. http:// cascadepolicy.org/pdf/pub/Oregon_Meth_Law.pdf

7. Asthma and Allergy Foundation of America. [Accessed July 22, 2013] Pseudoephedrine (PSE) awareness study—executive external report. http://aafa.org/pdfs/Executive\%20External\%20Report $\%$ 20FINAL1.pdf

8. Blumenschein, K.; Fink, JL., III; Freeman, PR., et al. [Accessed April 10, 2014] Independent evaluation of the Kentucky All Schedule Prescription Electronic Reporting (KASPER) program: executive summary. http://chfs.ky.gov/NR/rdonlyres/07E92D7D-97BD-4928A642-9FB8FA181C7F/0/KASPEREvaluationExecutiveSummary10152010.pdf

9. Harris PA, Taylor R, Thielke R, et al. Research Electronic Data Dapture (REDCap)—a metadatadriven methodology and workflow process for providing translational research informatics support. J Biomed Inform. 2009; 42(2):377-381. [PubMed: 18929686]

10. Substance Abuse and Mental Health Services Administration. [Accessed July 22, 2013] 20082010 national survey on drug use and health sub-state region definitions. www.samhsa.gov/data/ NSDUH/substate2k10/RegionDefinitions/NSDUHSubstateRegDefs2010.htm

11. Tan AC, Emmerton L. Non-prescription medicines: current issues in Australian community pharmacy. Int J Pharm Pract. 2009; 17(4):207-213. [PubMed: 20217945]

12. Foxhall K. R.Ph.s tag pseudoephedrine rules as a burden. Drug Topics. 2008; 152(1):30.

13. Lin AC, Huang YC, Punches G, et al. Effect of a robotic prescription-filling system on pharmacy staff activities and prescription-filling time. Am J Health Syst Pharm. 2007; 64(17):1832-1839. [PubMed: 17724365] 


\section{At a Glance}

Synopsis: This survey-based study of 431 community pharmacists in Kentucky found that fewer than $4 \%$ believe current controls against the use of precursor chemicals to produce methamphetamine are "very effective," while roughly one-half find electronic tracking and quantity limitations to be at least "somewhat effective." Comparatively, more than three-fourths of those surveyed anticipated that proposed legislation to make precursors such as pseudoephedrine (PSE) available on a prescription-only basis would be at least "somewhat effective" in reducing methamphetamine abuse and methamphetamine-related laboratory incidents. However, a majority of responding pharmacists also anticipated that such legislation would impact patients in a variety of ways, including limiting access to PSE for legitimate use.

Analysis: Methamphetamine abuse and production in clandestine laboratories appears to be increasing in Kentucky, but there is lack of consensus on how best to address this problem. The majority of pharmacists (56.2\%) surveyed for this study support proposed legislation to reclassify PSE as a legend drug available by prescription only, with those working in chain pharmacies 2.9 times more likely than independent pharmacists to voice their support. This may be attributable to independent pharmacists' comparative flexibility in instituting individualized store policies regarding PSE purchases. It is hoped that future legislation will effectively reduce methamphetamine production, laboratory incidents, and abuse in Kentucky while minimizing inconvenience and cost to lawabiding citizens. 


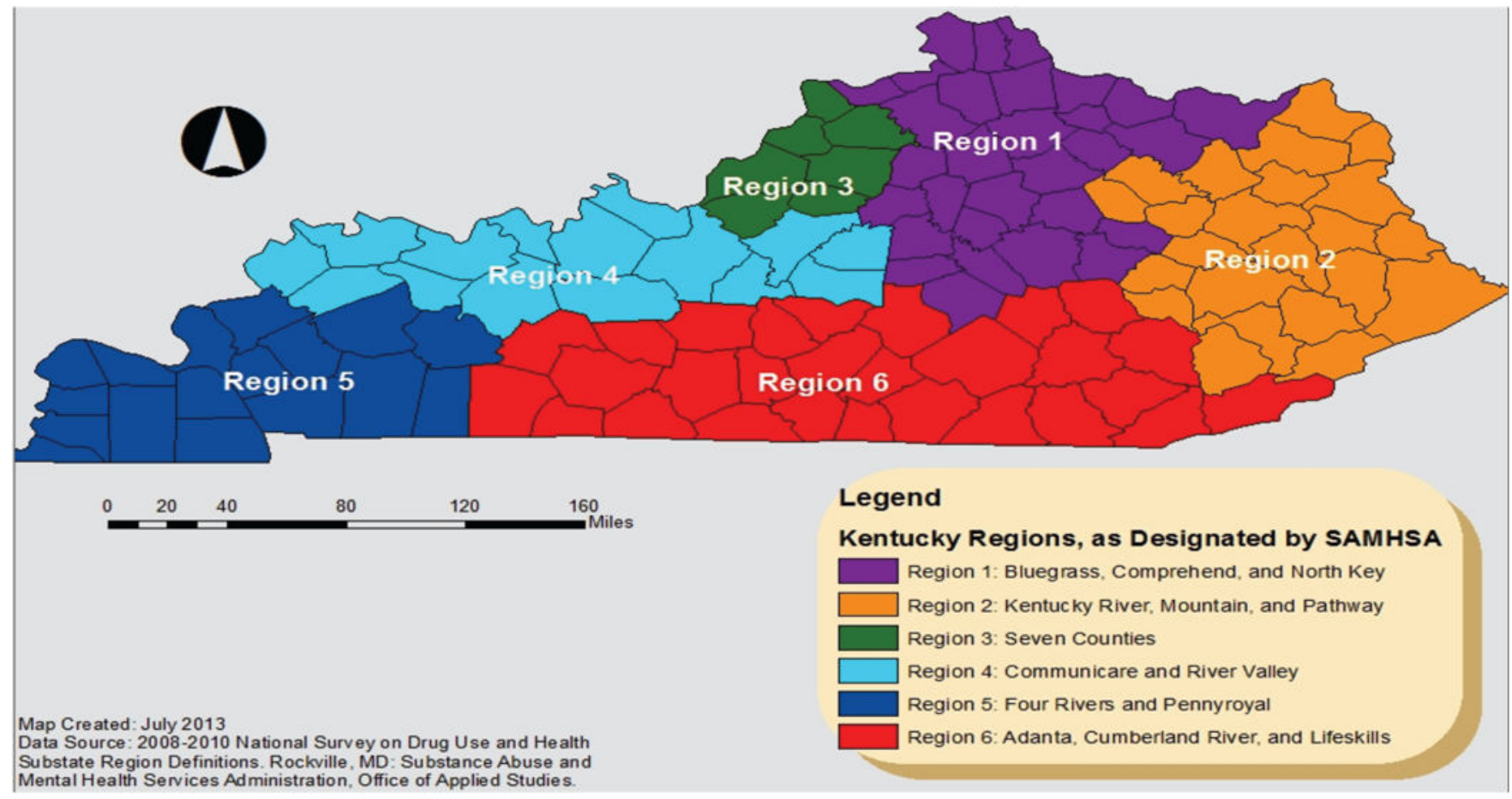

Figure 1. Kentucky regions in 2010 as defined by Substance Abuse and Mental Health Services Administration (SAMHSA) 


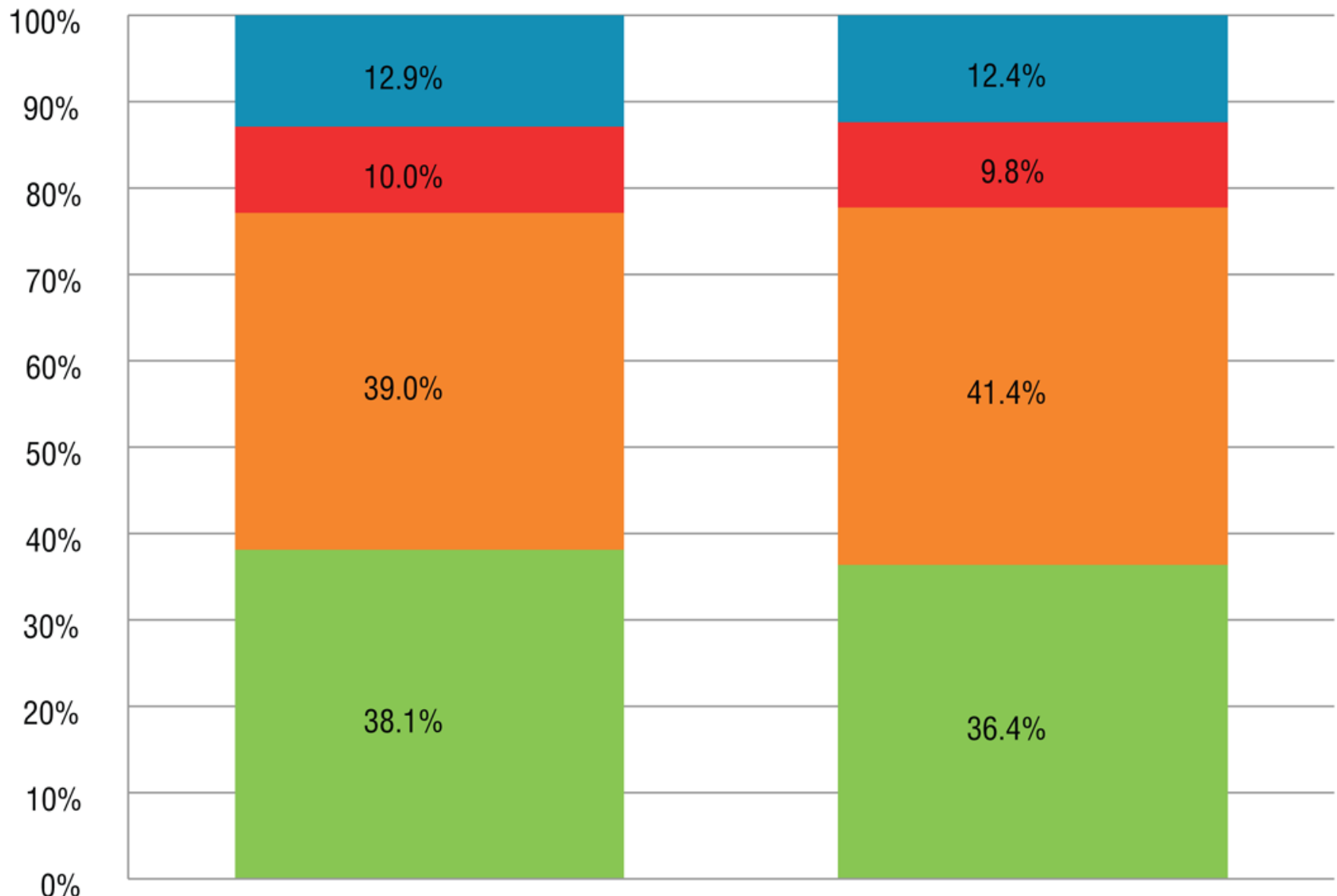

Rx-only efficacy at reducing meth abuse $(n=428)$

- Not effective at all

- Somewhat ineffective

- Somewhat effective

Rx-only efficacy at reducing meth lab incidents $(n=420)$

Figure 2. Pharmacists' anticipated efficacy of proposed legislation to make PSE a legend drug Abbreviations used: meth, methamphetamine; PSE, pseudoephedrine; Rx-only, prescription only. 


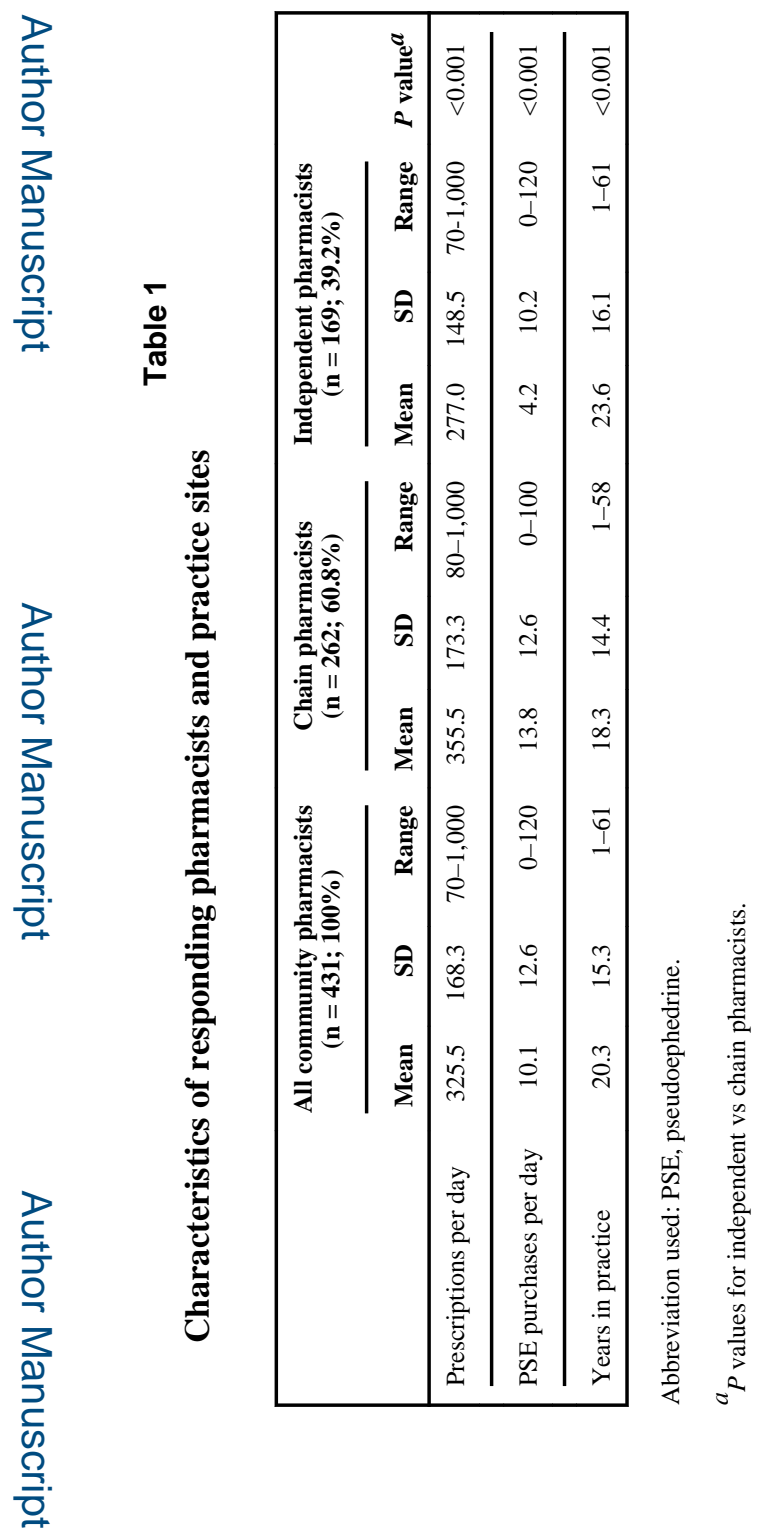



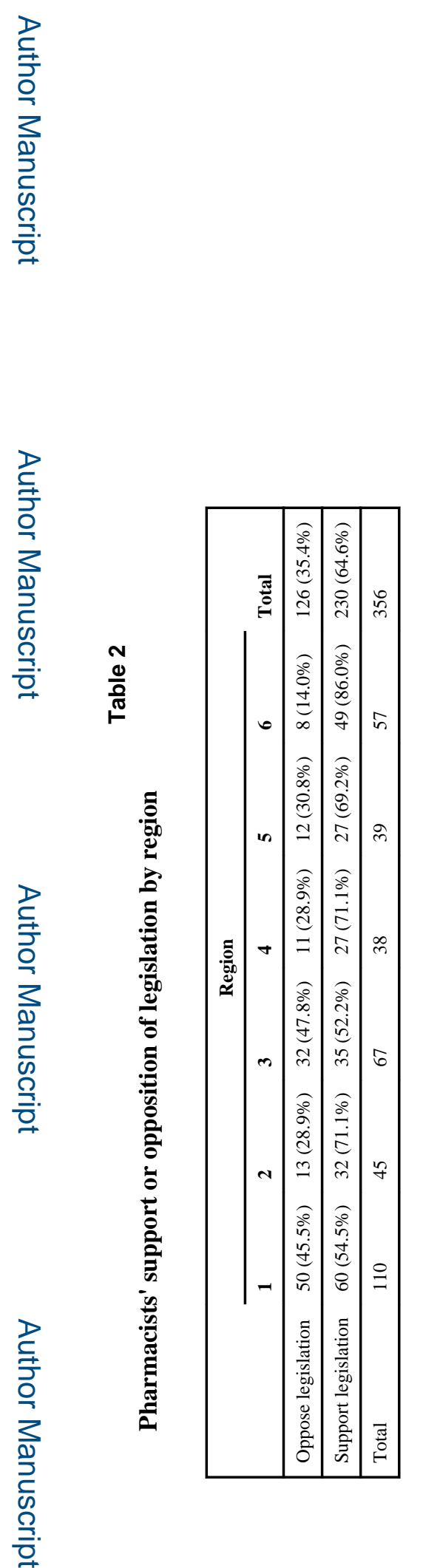

$J$ Am Pharm Assoc (2003). Author manuscript; available in PMC 2015 March 02. 
Table 3

Logistic regression model for pharmacists supporting the legislation to make PSE available by prescription only $(n=342)$

\begin{tabular}{|c|c|c|}
\hline & Odds ratio $(95 \% \mathrm{CI})$ & Pvalue \\
\hline \multicolumn{3}{|l|}{ Practice site } \\
\hline Independent pharmacists & $\ldots$ & \\
\hline Chain pharmacists & $2.90(1.27-6.60)$ & 0.011 \\
\hline \multicolumn{3}{|c|}{ Anticipated impact on time spent on PSE activities } \\
\hline Increase in time & $\ldots$ & \\
\hline No change in time & $5.09(1.77-14.65)$ & 0.003 \\
\hline Decrease in time & $10.57(4.42-25.30)$ & $<0.001$ \\
\hline \multicolumn{3}{|l|}{ Anticipated impact on pharmacy profits } \\
\hline Reduced profits & $\ldots$ & \\
\hline Increased profits & $9.45(1.80-49.5)$ & 0.008 \\
\hline Neutral financial impact & $4.53(1.64-12.45)$ & 0.003 \\
\hline Uncertain & $3.78(1.27-11.26)$ & 0.017 \\
\hline \multicolumn{3}{|l|}{ Regions } \\
\hline Region 1 & $\ldots$ & \\
\hline Region 2 & $4.57(1.34-15.59)$ & 0.015 \\
\hline Region 3 & $1.89(0.66-5.44)$ & 0.235 \\
\hline Region 4 & $8.17(1.71-39.03)$ & 0.008 \\
\hline Region 5 & $4.04(1.19-13.79)$ & 0.025 \\
\hline Region 6 & $7.99(2.34-27.30)$ & 0.001 \\
\hline \multicolumn{3}{|c|}{ Perceived efficacy of reducing methamphetamine abuse } \\
\hline Not effective & $\ldots$ & \\
\hline Somewhat ineffective & $1.52(0.26-9.02)$ & 0.646 \\
\hline Somewhat effective & $8.22(1.94-34.93)$ & 0.004 \\
\hline Very effective & $34.05(5.89-196.97)$ & $<0.001$ \\
\hline \multicolumn{3}{|c|}{ Perceived efficacy of reducing methamphetamine lab incidents } \\
\hline Not effective & $\ldots$ & \\
\hline Somewhat ineffective & $2.26(0.38-13.55)$ & 0.372 \\
\hline Somewhat effective & $2.56(0.70-9.32)$ & 0.155 \\
\hline Very effective & $8.47(1.68-42.60)$ & 0.010 \\
\hline No opinion & $4.92(0.56-43.54)$ & 0.152 \\
\hline \multicolumn{3}{|c|}{ Confidence in identifying patients using PSE for a legitimate purpose } \\
\hline Extremely confident & $\ldots$ & \\
\hline Somewhat confident & $0.67(0.30-1.54)$ & 0.349 \\
\hline Not confident & $0.81(0.14-4.58)$ & 0.810 \\
\hline Not applicable & $0.81(0.05-13.54)$ & 0.883 \\
\hline Grams of PSE sold per county resident & $0.51(0.13-1.99)$ & 0.336 \\
\hline
\end{tabular}


Abbreviation used: PSE, pseudoephedrine. 